\title{
Thermodynamic model of a hybrid Brayton thermosolar plant
}

\author{
R.P. Merchán, M.J. Santos*, A. Medina, A. Calvo Hernández \\ Department of Applied Physics, University of Salamanca, 37008, Salamanca, Spain
}

\section{A $\quad$ R $T$ T I I C L E}

\section{Article history:}

Received 16 January 2017

Received in revised form 23 May 2017

Accepted 26 May 2017

Available online 31 May 2017

\section{Keywords:}

Thermosolar gas-turbines

Hybrid plants

Thermodynamic model

Variable solar irradiance

Global plant performance

Seasonal evolution

\begin{abstract}
A B S T R A C T
We present a thermodynamic model for the prediction of the performance records of a solar hybrid gas turbine power plant. Variable irradiance and ambient temperature conditions are considered. A serial hybridization is modeled with the aim to get an approximately constant turbine inlet temperature, and thus to deliver to the grid a stable power output. The overall thermal efficiency depends on the efficiencies of the involved subsystems and the required heat exchangers in a straightforward analytical way. Numerical values for input parameters are taken from a central tower heliostat field recently developed near Seville, Spain. Real data for irradiance and external temperature are taken in hourly terms. Curves for the evolution of plant efficiencies (solar, gas turbine, fuel conversion efficiency, overall efficiency, etc.) and solar share are presented for representative days of each season. The cases of nonrecuperative and recuperative plant configurations are shown. Estimations of the hourly evolution of fuel consumption are simulated as well as savings between the hybrid solar operation model and the pure combustion mode. During summer, fuel saving can reach about $11.5 \%$ for a recuperative plant layout. In addition, plant emissions for several configurations are presented.
\end{abstract}

(c) 2017 Elsevier Ltd. All rights reserved.

\section{Introduction}

Along the last years a number of experimental facilities based on the concept of hybrid solar gas turbines were developed. In these projects concentrated solar power [1,2] coming from a central receiver plant is used to heat pressurized air following a Braytonlike cycle [3-5]. This technology may be especially interesting for regions with advantageous solar conditions [6]. This is in turn associated to water shortage. Brayton cycles admit combinations with other cycles in order to improve overall efficiency by making use of high temperature output heat $[7,8]$.

In this context the term hybrid means that during low solar radiation time spans a combustion chamber ensures a stable power release to the grid and makes not imperative the utilization of storage systems [9]. Different hybridization techniques have been proposed [10]. Hybridization can be performed starting from an existing standard fossil plant or developing an original hybrid plant sketch [11]. Usually there is more flexibility within the second option, provided that design challenges are properly worked out. Nowadays, it is necessary a rigorous simulation work considering

\footnotetext{
* Corresponding author.

E-mail addresses: rpmerchan@usal.es (R.P. Merchán), smjesus@usal.es (M.J. Santos), amd385@usal.es (A. Medina), anca@usal.es (A. Calvo Hernández).
}

the hybrid system as a whole. Technological, thermodynamic, and economic ingredients should be simultaneously considered in this design process $[7,10,12]$. In such a task it is difficult to avoid the election of particular stationary conditions for solar irradiance and ambient temperature. Nevertheless, design point conditions are usually too hopeful and do not reflect the actual fluctuating behavior due to daily and seasonal changes of solar irradiance at the elected location.

During the last years several research works on the model, analysis, and simulation of this technology have been published. A considerable amount of them make use of commercial simulation environments or software developed by research groups which allows for a detailed description and specific calculations on the solar subsystem and any plant component $[3,13]$. With respect to solar collectors, exhaustive computations for the solar efficiency including mirror area, spillage, blocking and shadowing effects, mirror tracking strategies, etc. have been developed [14,15]. These simulations lead to complete information for each plant component, managing a large amount of variables and parameters. In consequence, optimization procedures are not easy to apply. Furthermore, it is not straightforward to extract physical information about the main sources of thermal losses in this kind of plants and to plan global strategies for the optimization of the plant design and operation.

From another point of view, there are several theoretical works 


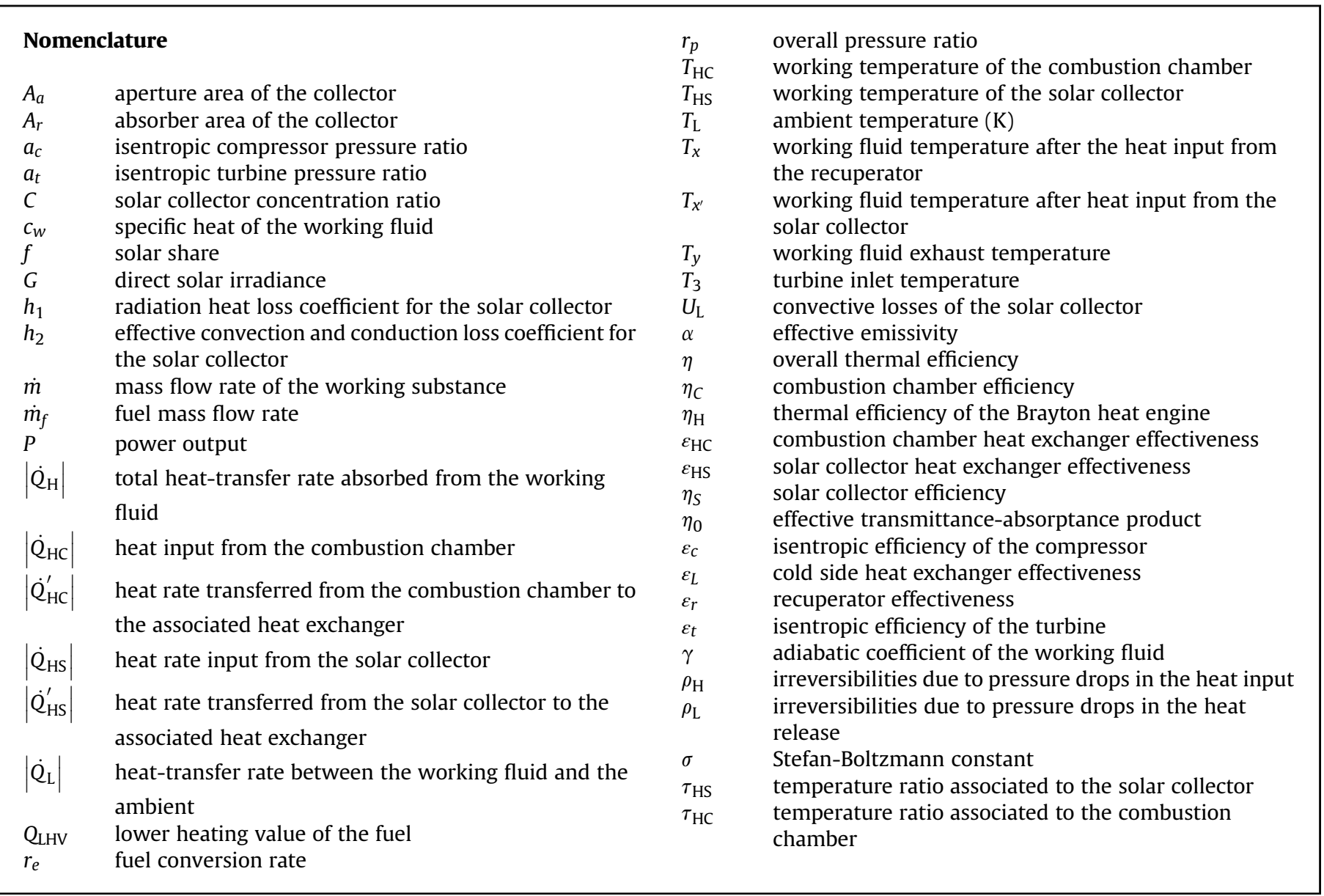

that model the plant starting from the ideal Brayton cycle for the power cycle and from a simple model for the solar subsystem. Then, the thermodynamic model is refined by incorporating submodels for thermal losses in order to provide more realistic output records [16-20]. This working method allows to obtain closed and general analytical expressions for thermal efficiencies and power output, and then check the model predictions for any design point conditions, with fixed values of solar irradiance and ambient temperature. This kind of models is also interesting for optimization purposes because lead to a realistic representation of real systems in terms of a reduced set of parameters.

Within the latter modus operandi, we present a thermodynamic cycle for the modeling of the considered solar plants that starts from a closed Brayton cycle however incorporating the main losses sources: non-ideal turbine and compressor, pressure decays, heat exchangers, heat transfer losses in the solar collector, combustion inefficiencies, etc. The model is flexible and allows to check the performance of several plant configurations. Temperature dependent specific heats for the working fluid are considered. Special emphasis will be paid on recuperation because of its key influence on the plant output records [6,21,22]. The model is dynamic in which refers to solar irradiance and ambient temperature. It allows to obtain curves for any plant output record in terms of those parameters and to analyze hourly and seasonal changes at any given location.

The model includes not too complex submodels for the solar subsystem and the power unit. This allows to get expressions for the plant global efficiency and other performance data in terms of a reduced number of parameters, with clear physical meaning. So, the proposed model constitutes a pre-design simulation scheme in order to understand the main bottlenecks to consider in the design of this kind of facilities. It will be shown that the comparison of its predictions with real plant data at particular conditions is fairly adequate. A whole analysis of plant records evolution along a year is undertaken. Real solar irradiance and ambient temperature measures for representative days of each season and a particular location are considered. Fuel consumption, pollutant, and greenhouse emissions will be evaluated.

\section{Thermodynamic plant model}

The layout of the hybrid solar plant considered is represented in Fig. 1 (a). A single step recuperative closed Brayton cycle is hybridized in order to obtain a stable power output, independent of the solar irradiance conditions. The design is flexible because the plant can work in different modes: with or without solar hybridization (depending on irradiance conditions), and with or without recuperator. Next we briefly describe the main thermodynamic processes experienced by the working fluid.

The working fluid at the compressor exit (temperature $T_{2}$ ) is heated up through a recuperator that makes use of the high temperature of the gas after the turbine, $T_{4}$. The temperature of the fluid at the recuperator exit, $T_{x}$, is elevated first by the heat released by the central tower solar subsystem if solar irradiance is enough. Afterwards, the fluid reaches a higher temperature, $T_{X^{\prime}}$ and then, in the last heating step, it receives an energy input from a combustion chamber through another heat exchanger. The final temperature at the turbine inlet, $T_{3}$, is taken as approximately constant, so the 


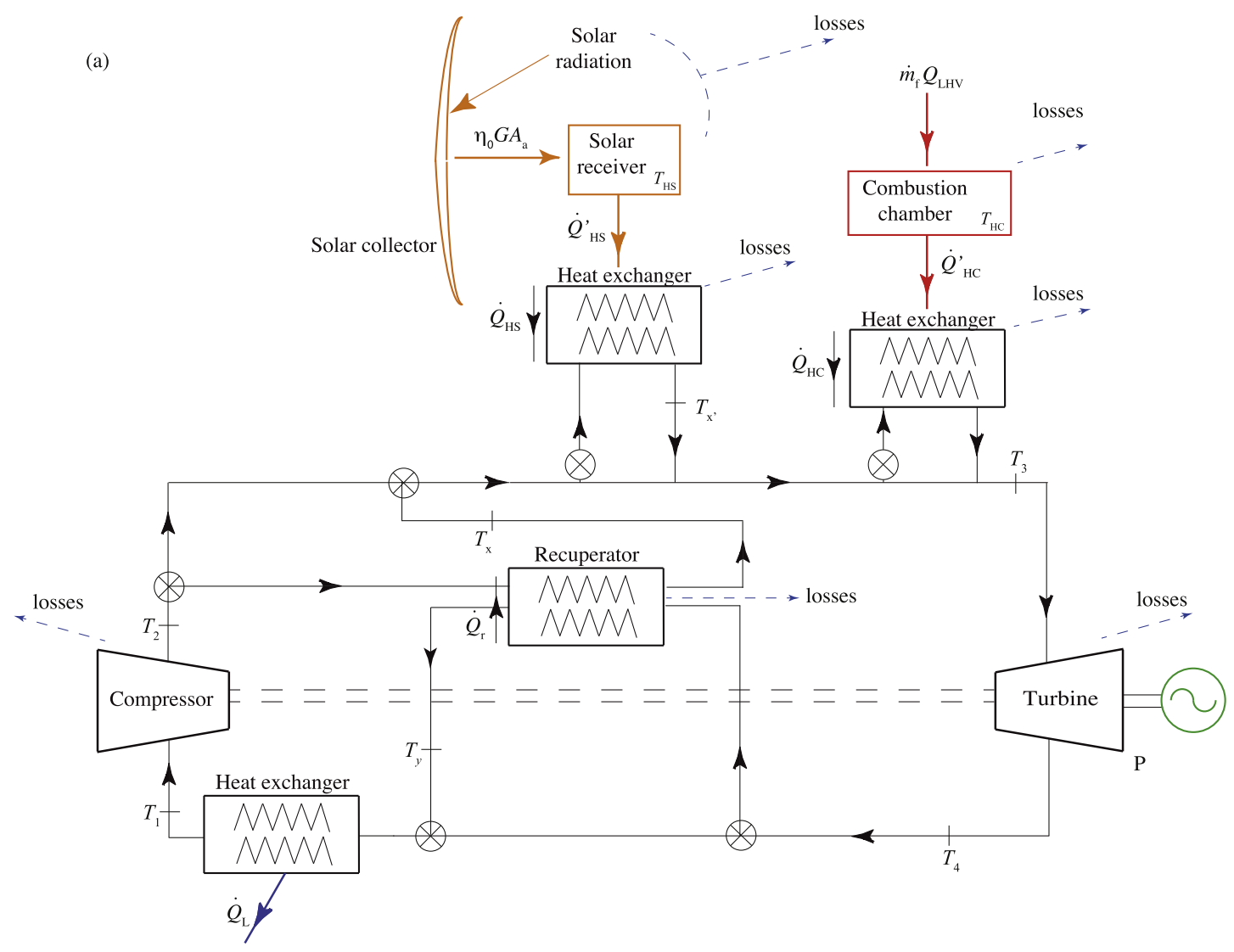

(b)

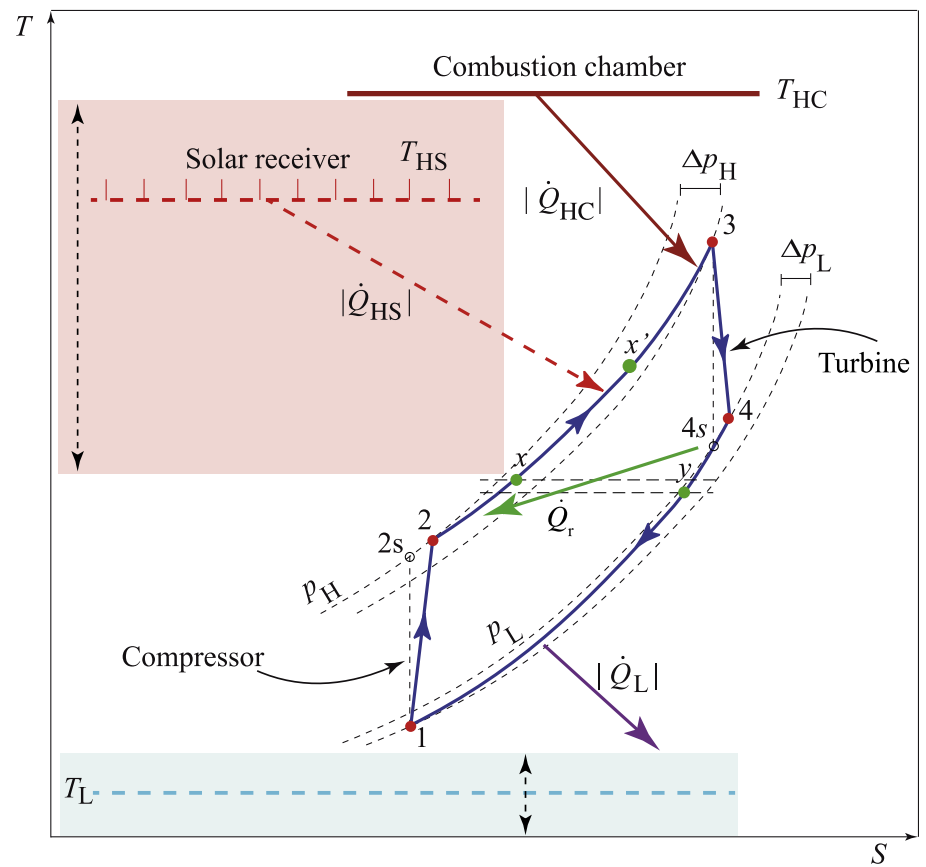

Fig. 1. (a) Scheme of the hybrid solar gas-turbine plant considered. The main heat transfers and temperatures are depicted. Also the key losses sources considered in the model are shown. (b) $T-S$ diagram of the irreversible Brayton cycle experienced by the working fluid.

power released by the installation to the grid is stable. In the case of insufficient irradiance a shut-off valve redirects the fluid directly to the heat exchanger below the combustion chamber.

From now on, the nomenclature for the different heat transfers in the model is detailed. The solar subsystem receives a heat input from the sun given by $G A_{a}$ where $G$ is the direct solar irradiance and $A_{a}$ the aperture area of the solar field. The solar irradiance is a function of time because it depends on the sun position during the day, weather conditions, and seasonal fluctuations. After discounting the losses, the receiver releases a useful energy to a heat 
exchanger, $\dot{Q}_{\mathrm{HS}}^{\prime}$, that in turn releases a final heat rate $\dot{Q}_{\mathrm{HS}}$ to the working fluid.

A similar scheme is followed to describe the combustion chamber subsystem. The energy input in this subsystem is $\dot{m}_{f} Q_{L H V}$, where $\dot{m}_{f}$ is the fuel mass consumption rate and $Q_{L H V}$ its corresponding lower heating value. The mass fuel rate will be also considered as time dependent, in accordance to the fluctuations of $G$. It should compensate variations in $G$ in such a way that the turbine inlet temperature remains approximately constant in all conditions. In the combustion chamber losses due to incomplete combustion and heat transfers to the surroundings are accounted for. The heat rate received by the working fluid from combustion of the fuel is denoted as $\dot{Q}_{\mathrm{HC}}$. The effectivenesses of the heat exchangers associated to the solar and the combustion subsystems are denoted as $\varepsilon_{\mathrm{HS}}$ and $\varepsilon_{\mathrm{HC}}$, respectively. The internal heat transfer associated to recuperation is called $\dot{Q}_{r}$. In order to close the thermodynamic cycle a cold-side heat exchanger is considered. The compressor inlet temperature, $T_{1}$, depend on the external temperature, $T_{L}$, that will fluctuate due to daily and seasonal changes. Thus, all other temperatures in the cycle oscillate because of the same reasons. The plant delivers a mechanical power output, $P$, independent of solar radiation fluctuations.

\subsection{Overall plant efficiency}

The thermal efficiency of the whole system, $\eta$, is the ratio between the net mechanical power output, $P$, and the total heat input rate,

$\eta=\frac{P}{G A_{a}+\dot{m}_{f} Q_{\mathrm{LHV}}}$

The following objective is to express this global efficiency in terms of the efficiency of the solar collector, $\eta_{S}$, that of the combustion chamber, $\eta_{\mathrm{C}}$, the efficiency of the Brayton heat engine, $\eta_{\mathrm{H}}$, and the effectivenesses of all the required heat exchangers. Details of the calculations can be found in Ref. [19].

The overall efficiency of the whole system, $\eta$, is obtained as:

$\eta=\eta_{\mathrm{S}} \eta_{\mathrm{C}} \eta_{\mathrm{H}}\left[\frac{\varepsilon_{\mathrm{HS}} \varepsilon_{\mathrm{HC}}}{\eta_{\mathrm{C}} \varepsilon_{\mathrm{HC}} f+\eta_{\mathrm{S}} \varepsilon_{\mathrm{HS}}(1-f)}\right]$

This expression is valid for the hybrid mode when both heat sources are simultaneously releasing energy to the fluid. In the particular case in which eventually all the energy input comes from the solar collector, $f=1$, and $\eta=\eta_{\mathrm{S}} \eta_{\mathrm{H}} \varepsilon_{\mathrm{HS}}$, and when solar irradiance is null, and the turbine works only with the heat released in the combustion reactions, $f=0$, and $\eta=\eta_{C} \eta_{\mathrm{H}} \varepsilon_{\mathrm{HC}}$.

It is also interesting to define a performance relative to the energy input with an economical cost, i.e., to the fuel burned. It constitutes a fuel conversion rate, and can be defined as suggested by Heywood [23] for internal combustion engines, $r_{e}=P /\left(\dot{m}_{f} Q_{\mathrm{LHV}}\right)$. It is easy to show that:

$r_{e}=\frac{\eta \eta_{S} \eta_{H} \varepsilon_{\mathrm{HS}}}{\eta_{S} \eta_{H} \varepsilon_{\mathrm{HS}}-\eta f}$

In the particular case all the energy input comes from combustion, $f=0$, and $r_{e}=\eta$. In the opposite limit, if eventually all the energy was solar, $f=1$, and $\eta=\eta_{S} \eta_{H} \varepsilon_{\mathrm{HS}}$, so $r_{e} \rightarrow \infty$.

\subsection{Solar collector and combustion efficiencies}

We consider a simple model for the concentrating solar system in order to be able to obtain analytical closed expressions for the overall plant efficiency. At low and intermediate working temperatures for the solar collector, $T_{H S}$, losses essentially comes from conduction and convection. At high temperatures radiation losses become significant and should be considered in any model. The energy collected at the aperture is $G A_{a}$, and the useful energy provided by the solar plant, $\left|\dot{Q}_{\mathrm{HS}}^{\prime}\right|$, is the difference between the energy transmitted to the receiver, $\eta_{0} G A_{a}$, and the losses. $\eta_{0}$ is the effective optical efficiency considering losses coming from spillage, shadowing, blocking, sun position effects, and so on. Thus, the useful heat released from the collector and its efficiency can be respectively expressed, as [24,25]:

$$
\left|\dot{Q}_{\mathrm{HS}}^{\prime}\right|=\eta_{0} G A_{a}-\alpha \sigma A_{r} T_{L}^{4}\left(\tau_{\mathrm{HS}}^{4}-1\right)-U_{L} A_{r} T_{L}\left(\tau_{\mathrm{HS}}-1\right)
$$

$\eta_{\mathrm{S}}=\frac{\left|\dot{Q}_{\mathrm{HS}}^{\prime}\right|}{G A_{a}}=\eta_{0}\left[1-h_{1} T_{L}^{4}\left(\tau_{\mathrm{HS}}^{4}-1\right)-h_{2} T_{L}\left(\tau_{\mathrm{HS}}-1\right)\right]$

In Eqs. (4) and (5), $\tau_{\mathrm{HS}}=T_{\mathrm{HS}} / T_{L}$ denotes the ratio between the working temperature of the solar receiver, $T_{\mathrm{HS}}$, and the surroundings, $T_{L} . A_{a}$ and $A_{r}$ are, respectively, the total area of the reflectors and the area of the receiver, $h_{1}=\alpha \sigma /\left(\eta_{0} G C\right), h_{2}=U_{L} /\left(\eta_{0} G C\right)$ are losses parameters, where $U_{L}$ is the convective heat loss coefficient, $\alpha$ is the effective emissivity of the collector, $C=A_{a} / A_{r}$ is the concentration ratio, and $\sigma$ the Stefan-Boltzmann constant. It will be considered in our model that the direct solar irradiance, $G$, and the surroundings temperature, $T_{L}$, are time functions because oscillate during a day and change with seasonal and meteorological conditions. For each particular pair of values of $G$ and $T_{L}$ at any given instant, the working temperature of the receiver, $T_{\mathrm{HS}}$, is calculated by balancing the energy received from the sun and that released to the working fluid experiencing the bottoming thermal cycle [18]. The heat released by the solar subsystem to the working fluid is $\left|\dot{Q}_{\mathrm{HS}}\right|=\varepsilon_{\mathrm{HS}}\left|\dot{Q}_{\mathrm{HS}}^{\prime}\right|$, where $\varepsilon_{\mathrm{HS}}=\left(T_{X^{\prime}}-T_{X}\right) /\left(T_{\mathrm{HS}}-T_{X}\right)$.

The efficiency of the combustion chamber, $\eta_{C}$, for a certain fuel and fuel-air equivalence ratio, can be considered as a constant parameter. In real equipment it could slightly change with fluctuations of the fuel-air equivalence ratio, the composition of the fuel, its temperature, and several other variables, but we are more interested in an adequate qualitative description. The heat received by the working fluid from the combustion chamber, $\dot{Q}_{\mathrm{HC}}$, can be written as:

$\left|\dot{Q}_{\mathrm{HC}}\right|=\varepsilon_{\mathrm{HC}}\left|Q_{\mathrm{HC}}^{\prime}\right|=\varepsilon_{\mathrm{HC}} \eta_{\mathrm{C}} \dot{m}_{f} Q_{\mathrm{LHV}}$

By expressing the effectiveness of the heat exchanger in between the combustion chamber and the thermal cycle as (see Fig. 1) $\varepsilon_{\mathrm{HC}}=\left(T_{3}-T_{X^{\prime}}\right) /\left(T_{\mathrm{HC}}-T_{X^{\prime}}\right)$, the heat released, in terms of temperatures, is:

$\left|\dot{Q}_{\mathrm{HC}}\right|=\dot{m} c_{w}\left(T_{3}-T_{X^{\prime}}\right)=\dot{m} c_{w} \varepsilon_{\mathrm{HC}}\left(T_{\mathrm{HC}}-T_{X^{\prime}}\right)$

where $\dot{m}$ is the working fluid mass flow and $c_{w}$ is its specific heat. The effective temperature in the combustion chamber is denoted as $T_{\mathrm{HC}}$, and the associated temperature ratio as $\tau_{\mathrm{HC}}=T_{\mathrm{HC}} / T_{L}$. As fluctuations in $G$ and $T_{L}$ are be taken into account, the fuel mass flow to be burned in the combustion chamber will also be a time dependent function in general given by:

$\dot{m}_{f}=\frac{\dot{m} c_{w}\left(T_{3}-T_{\chi^{\prime}}\right)}{\eta_{C} Q_{\mathrm{LHV}} \varepsilon_{\mathrm{HC}}}$

where $T_{X^{\prime}}$ will vary with the solar irradiance and ambient conditions. The rate of fuel mass burned can be also obtained from the fuel conversion rate, $r_{e}$, as: $\dot{m}_{f}=P /\left(r_{e} Q_{\mathrm{LHV}}\right)$. 


\subsection{Brayton gas-turbine efficiency}

The main assumptions considered for evaluating the efficiency of the heat engine, $\eta_{\mathrm{H}}$, will be briefly outlined since the model has been detailed elsewhere in previous works by our group [19,22]. It is assumed that a mass rate of an ideal gas, $\dot{m}$, undergoes an irreversible closed recuperative Brayton cycle. The specific heat of the working fluid is taken as temperature dependent, $c_{w}(T)$. This point constitutes a substantial improvement of this model over previous ones where an averaged, constant specific heat, was supposed $[19,22]$. The $T-S$ diagram of the cycle is depicted in Fig. 1(b), where it is stressed that both the working temperature of the solar receiver, $T_{\mathrm{HS}}$ and that of the surroundings, $T_{L}$, are fluctuating quantities.

1. As starting step the gas is compressed $(1 \rightarrow 2)$ by means of a nonideal compressor. Its isentropic efficiency is given by $\varepsilon_{c}=\left(T_{2 s}-T_{1}\right) /\left(T_{2}-T_{1}\right)$. In this equation $T_{2 s}$ represents the temperature of the working fluid after the compression process if it was adiabatic and $T_{2}$ is the actual temperature at the compressor outlet.

2. Between states 2 and 3, in the most general situation, the gas receives three energy inputs in sequence. First, the non-ideal recuperator increases the gas temperature from $T_{2}$ to $T_{x}$. Its effectiveness, $\varepsilon_{r}$, is defined as the ratio between the actual temperature $\left(T_{x}-T_{2}\right)$ increase and the maximum ideal one $\left(T_{4}-T_{2}\right): \varepsilon_{r}=\left(T_{x}-T_{2}\right) /\left(T_{4}-T_{2}\right)=\left(T_{y}-T_{4}\right) /\left(T_{2}-T_{4}\right)$. In the case of a non-recuperative cycle, $\varepsilon_{r}=0$, and in the ideal limit, $\varepsilon_{r}=1$.

Secondly, the gas receives a heat flow, $\left|\dot{Q}_{\mathrm{HS}}\right|$, from the solar subsystem (step $x \rightarrow x^{\prime}$ ) and thus its temperature increases from $T_{x}$ to $T_{x^{\prime}}$. Finally, the gas receives a completing heat input from the combustion chamber $\left(x^{\prime} \rightarrow 3\right)$ in order to ensure an approximately constant turbine inlet temperature, $T_{3}$, independently of the solar irradiance conditions.

Pressure decrease in the process $2 \rightarrow 3$ is quantified through an effective parameter, $\rho_{\mathrm{H}}$. In real plants pressure decays are associated to the particular equipment in any of the three steps of the heat input process, so the curve $2 \rightarrow 3$ would not be as smooth as it is plotted in Fig. 1(b). But the consideration of a unique global pressure decay parameter allows to obtain analytical equations and to numerically check the effects of pressure decays in the output parameters of the plant [13]. This parameter, $\rho_{\mathrm{H}}$, is defined as:

$\rho_{\mathrm{H}}=\frac{p_{\mathrm{H}}-\Delta p_{\mathrm{H}}}{p_{\mathrm{H}}}$

where $p_{\mathrm{H}}$ is the highest pressure of the gas and $p_{\mathrm{H}}-\Delta p_{\mathrm{H}}$ its pressure at the turbine inlet.

3. In the state 3 the working fluid has reached its maximum temperature and it is expanded by means of a non-ideal turbine performing the power stroke $(3 \rightarrow 4)$. In Fig. $1(\mathrm{~b})$ the state $4 s$ represents the final state in the ideal case the turbine behaves isentropically, and the state 4 is the actual final state after expansion. The isentropic efficiency of the turbine, $\varepsilon_{t}$, is given by: $\varepsilon_{t}=\left(T_{4}-T_{3}\right) /\left(T_{4 s}-T_{3}\right)$.

4. Lastly, the gas recovers the conditions at the initial state 1 by releasing heat in the process $4 \rightarrow 1$ through two steps. First, by means of the recuperator (process $4 \rightarrow y$ ) and later by exchanging heat to the ambient through a non-ideal heat exchanger with effectiveness, $\varepsilon_{L}$ (process $y \rightarrow 1$ ): $\varepsilon_{\mathrm{L}}=\left(T_{1}-T_{y}\right) /\left(T_{L}-T_{y}\right)$.
The pressure loss during the whole heat release process is measured through a coefficient $\rho_{L}$ given by:

$\rho_{\mathrm{L}}=\frac{p_{\mathrm{L}}-\Delta p_{\mathrm{L}}}{p_{\mathrm{L}}}$

where $p_{\mathrm{L}}$ is the gas pressure at the turbine outlet and $p_{\mathrm{L}}-\Delta p_{\mathrm{L}}$ its lowest pressure during the cycle. It is convenient to define a global pressure ratio, $r_{p}$ as:

$r_{p}=\frac{p_{\mathrm{H}}}{p_{\mathrm{L}}-\Delta p_{\mathrm{L}}}$

Provided that the processes $1 \rightarrow 2 s$ and $3 \rightarrow 4 s$ are adiabatic (see Fig. 1(b)), two parameters, $a_{c}$ and $a_{t}$, related to the pressure ratios of the compressor and the turbine respectively are defined:

$a_{c}=\frac{T_{2 s}}{T_{1}}=\left(\frac{p_{\mathrm{H}}}{p_{L}-\Delta p_{L}}\right)^{\left(\bar{\gamma}_{12}-1\right) / \bar{\gamma}_{12}}=r_{p}^{\left(\bar{\gamma}_{12}-1\right) / \bar{\gamma}_{12}}$

$a_{t}=\frac{T_{3}}{T_{4 s}}=\left(\frac{p_{\mathrm{H}}-\Delta p_{\mathrm{H}}}{p_{L}}\right)^{\left(\bar{\gamma}_{34}-1\right) / \bar{\gamma}_{34}}$

where $\bar{\gamma}_{12}$ is the average adiabatic coefficient in the compression process and $\bar{\gamma}_{34}$ the corresponding one during expansion.

From Eqs. (9) and (10):

$\frac{p_{H}-\Delta p_{H}}{p_{L}}=\rho_{H} \rho_{L} r_{p}$

and so:

$a_{t}=\left(\rho_{H} \rho_{L} r_{p}\right)^{\left(\bar{\gamma}_{34}-1\right) / \bar{\gamma}_{34}}$

Both coefficients, $a_{t}$ and $a_{c}$ are not independent, both are related through the pressure ratio, $r_{p}$.

Once, the main hypotheses and parameters have been made explicit, we express the temperatures of all the states in the cycle in terms of the temperature of the solar collector, $T_{\mathrm{HS}}$, that of the combustion chamber, $T_{\mathrm{HC}}$, and the pressure ratios of the compressor, $a_{c}$ and the turbine, $a_{t}$. By using the definitions in the section above, it is possible to obtain the following set of equations:

$T_{1}=\varepsilon_{L} T_{L}+T_{y}\left(1-\varepsilon_{L}\right)$

$T_{2}=T_{1}+\frac{1}{\varepsilon_{C}}\left(T_{2 s}-T_{1}\right)=T_{1} Z_{c}$

$T_{3}=\varepsilon_{\mathrm{HC}} T_{\mathrm{HC}}+T_{X^{\prime}}\left(1-\varepsilon_{\mathrm{HC}}\right)$

$T_{4}=T_{3}-\varepsilon_{t}\left(T_{3}-T_{4 s}\right)=T_{3} Z_{t}$

$T_{x}=\varepsilon_{r} T_{4}+T_{2}\left(1-\varepsilon_{r}\right)$

$T_{y}=\varepsilon_{r} T_{2}+T_{4}\left(1-\varepsilon_{r}\right)$

$T_{X^{\prime}}=\varepsilon_{\mathrm{HS}} T_{\mathrm{HS}}+T_{X}\left(1-\varepsilon_{\mathrm{HS}}\right)$

The equations (17) and (19) were simplified by introducing two definitions:

$$
\begin{aligned}
& Z_{c}=1+\frac{1}{\varepsilon_{c}}\left(a_{c}-1\right) \\
& Z_{t}=1-\varepsilon_{t}\left(1-\frac{1}{a_{t}}\right)
\end{aligned}
$$


By simultaneously using Eqs. (16)-(22) it is feasible to express all the temperatures in terms of the temperatures of the heat sources, $T_{\mathrm{HS}}$ and $T_{\mathrm{HC}}$, the ambient temperature, $T_{L}$, the pressure ratio, $r_{p}$ and all the irreversibility parameters defined above. The following closed set of expressions is obtained: from Caterpillar, for which the manufacturer provides several specifications [27]. All the parameters required to obtain the numerical predictions can be found in Refs. [18,19]. Dry air was considered as working fluid, with polynomial fits for constant pressure specific heat taken from Ref. [28]. As highlighted before,

$\begin{aligned} & T_{2}= \frac{\left(1-\varepsilon_{L}\right)\left(1-\varepsilon_{r}\right)\left[\varepsilon_{\mathrm{HC}} T_{\mathrm{HC}}+\varepsilon_{\mathrm{HS}} T_{\mathrm{HS}}\left(1-\varepsilon_{\mathrm{HC}}\right)\right]+\varepsilon_{L} T_{L}\left[Z_{t}^{-1}-\left(1-\varepsilon_{\mathrm{HC}}\right)\left(1-\varepsilon_{\mathrm{HS}}\right) \varepsilon_{r}\right]}{\left[Z_{c}^{-1}-\left(1-\varepsilon_{L}\right) \varepsilon_{r}\right]\left[Z_{t}^{-1}-\left(1-\varepsilon_{\mathrm{HC}}\right)\left(1-\varepsilon_{\mathrm{HS}}\right) \varepsilon_{r}\right]-\left(1-\varepsilon_{\mathrm{HC}}\right)\left(1-\varepsilon_{\mathrm{HS}}\right)\left(1-\varepsilon_{L}\right)\left(1-\varepsilon_{r}\right)^{2}} \\ & T_{4}=\frac{\left[\varepsilon_{\mathrm{HC}} T_{\mathrm{HC}}+\varepsilon_{\mathrm{HS}} T_{\mathrm{HS}}\left(1-\varepsilon_{\mathrm{HC}}\right)\right]\left[Z_{c}^{-1}-\left(1-\varepsilon_{L}\right) \varepsilon_{r}\right]+\varepsilon_{L} T_{L}\left(1-\varepsilon_{\mathrm{HC}}\right)\left(1-\varepsilon_{\mathrm{HS}}\right)\left(1-\varepsilon_{r}\right)}{\left[Z_{c}^{-1}-\left(1-\varepsilon_{L}\right) \varepsilon_{r}\right]\left[Z_{t}^{-1}-\left(1-\varepsilon_{\mathrm{HC}}\right)\left(1-\varepsilon_{\mathrm{HS}}\right) \varepsilon_{r}\right]-\left(1-\varepsilon_{\mathrm{HC}}\right)\left(1-\varepsilon_{\mathrm{HS}}\right)\left(1-\varepsilon_{L}\right)\left(1-\varepsilon_{r}\right)^{2}}\end{aligned}$

It is easy to get all the temperature of the working fluid by substituting Eqs. (25) and (26) in Eqs. (16)-(22). The total heat input rate, $\left|\dot{Q}_{H}\right|$, and, the heat release, $\left|\dot{Q}_{L}\right|$, are expressed in terms of the temperatures in the following way:

$$
\begin{aligned}
& \left|\dot{Q}_{H}\right|=\left|\dot{Q}_{\mathrm{HS}}\right|+\left|\dot{Q}_{\mathrm{HC}}\right| \\
& \left|\dot{Q}_{L}\right|=\dot{m} \int_{T_{1}}^{T_{y}} c_{w}(T) d T
\end{aligned}
$$

where,

$$
\left|\dot{Q}_{\mathrm{HS}}\right|=\dot{m} \int_{T_{x}}^{T_{x^{\prime}}} c_{W}(T) d T=f\left|\dot{Q}_{H}\right|
$$

$\left|\dot{Q}_{\mathrm{HC}}\right|=\dot{m} \int_{T_{x^{\prime}}}^{T_{3}} c_{w}(T) d T=(1-f)\left|\dot{Q}_{H}\right|$

In these equations $c_{w}(T)$ represents the temperature dependent constant pressure specific heat of the working fluid. Thus, the power output released by the heat engine, $P=\left|\dot{Q}_{H}\right|-\left|\dot{Q}_{L}\right|$, and its thermal efficiency, $\eta_{\mathrm{H}}=P /\left|\dot{Q}_{\mathrm{H}}\right|$, have analytical expressions susceptible to be evaluated for any particular parameters arrangement. And so, from the considered models for the solar and the combustion chamber subsystems, it is possible to obtain the overall plant efficiency from Eq. (2).

\section{Numerical implementation}

The model presented in this work was validated for fixed solar irradiance conditions in previous works [18,19], where explicit tables containing model predictions and experimental results can be found. In this section we outline the main background and conclusions of the numerical validation. As validation target it was elected the central tower concentrating collector developed by Abengoa Solar near Seville, Spain, under the project called SOLUGAS [26]. The turbine used in the project is the model Mercury 50 the consideration of temperature dependent functions for working fluid specific heats constitutes a significant advance with respect to previous versions of our simulation scheme.

From now on, solar irradiance and ambient temperature are not be considered as fixed design parameters, but oscillating ones in terms of daily and seasonal conditions. This is one of the strengths of the purely thermodynamic scheme developed in this work: its capability to predict plant performance records for whichever solar and meteorological conditions.
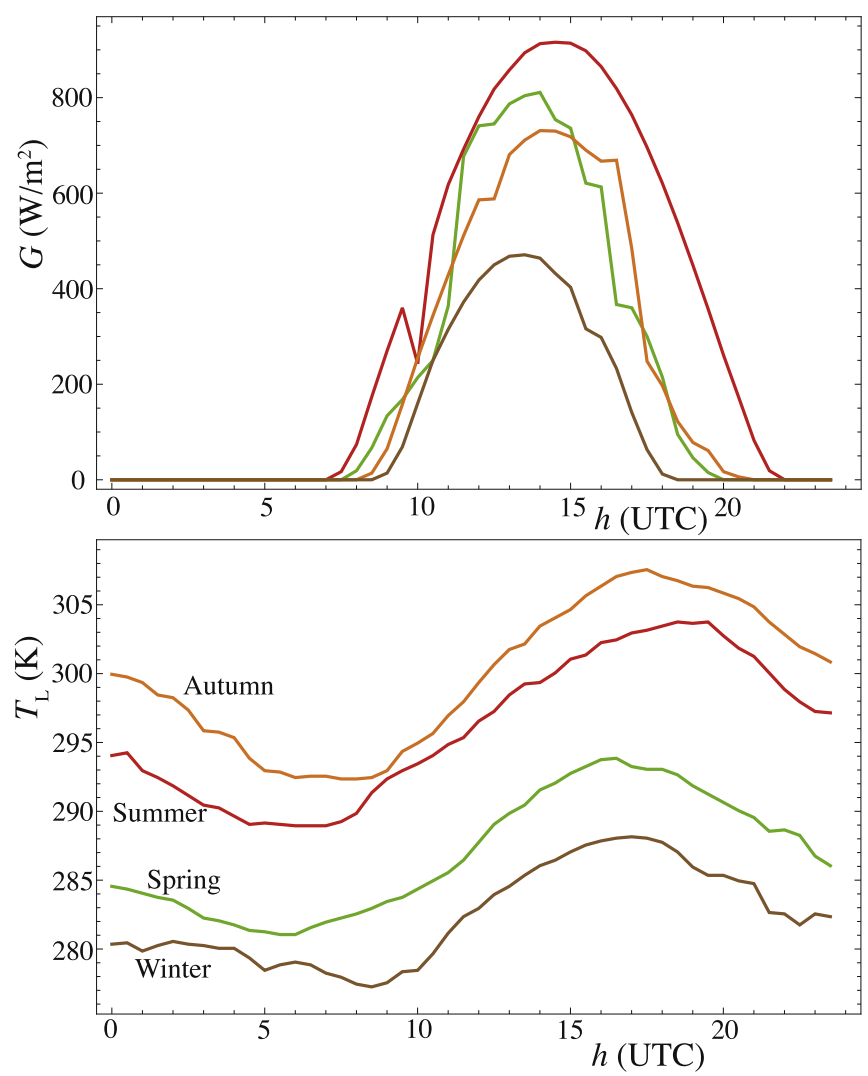

Fig. 2. Hourly direct irradiance, $G$, and ambient temperature, $T_{L}$, for four selected days at the beginning of each season at Seville [29]. Curves are neither smoothed nor averaged. 

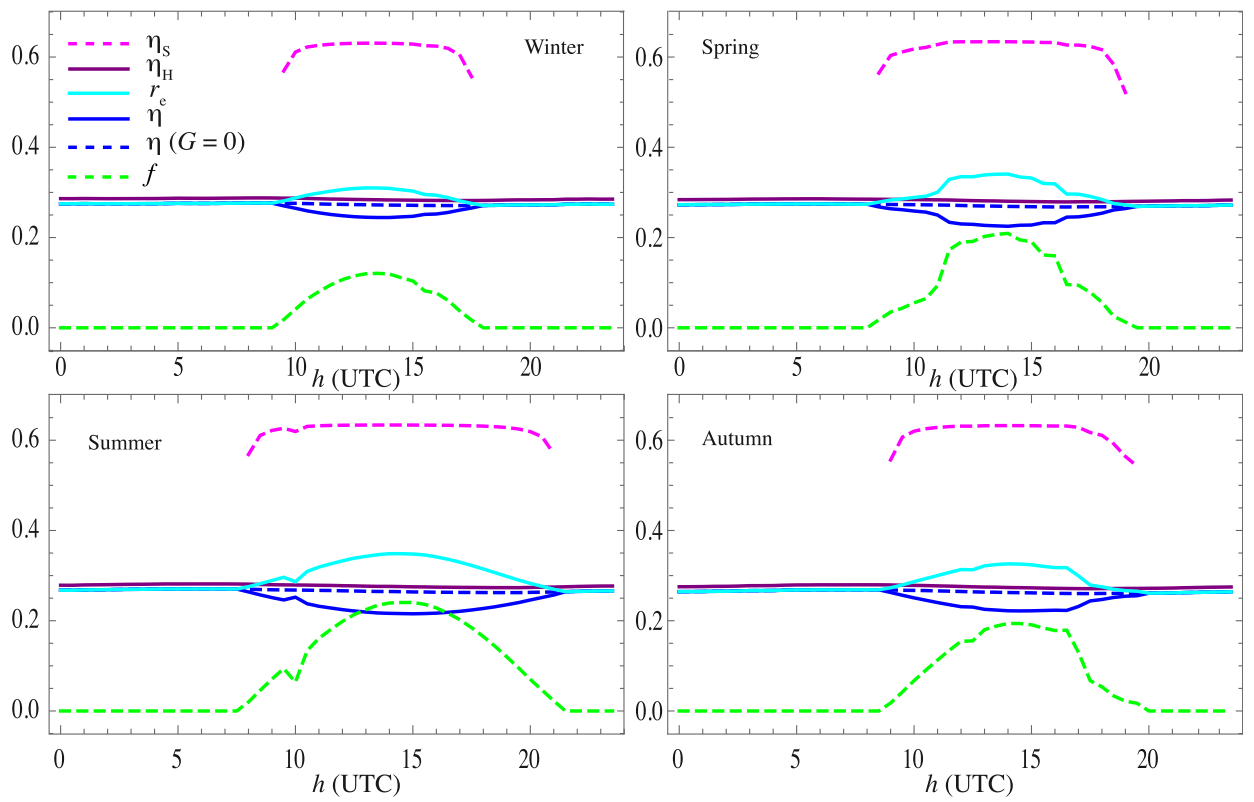

Fig. 3. Hourly evolution of plant efficiencies and solar share, $f$, for representative days of each season for a non-recuperative plant layout.

\subsection{Daily variations and seasonal variations of solar irradiance and ambient temperature}

Direct irradiance, $G$, and ambient temperature, $T_{L}$, were taken from a database by Meteosevilla [29] at a location very close to the installation of the project SOLUGAS, Sanlúcar La Mayor, Seville, Spain. We took data from four regular days in 2013, each corresponding to the beginning of a season (21st): March, June, September, and December. Data were taken every $30 \mathrm{~min}$. No smoothing or averaging procedures were followed. The curves for $G$ and $T_{L}$ are represented in Fig. 2 . Seville has a priori quite favorable solar conditions. The upper panel of the figure shows that the maximum value of $G$ reached in summer is about $875 \mathrm{~W} / \mathrm{m}^{2}$. The maximum of the less favorable month, December reaches about $480 \mathrm{~W} / \mathrm{m}^{2}$. The number of insolation hours is quite elevated. At the same time ambient temperatures are relatively high. They reach maximum values around $34{ }^{\circ} \mathrm{C}$ during the day in September and minimum values about $4{ }^{\circ} \mathrm{C}$ in winter.

For each pair of values of $G$ and $T_{L}$ the working temperature of the collector, $T_{H S}$ was calculated. All the results presented in this work were obtained from our own software, developed in programming language Mathematica ${ }^{\circledR}$. In the next sections, results with plant configurations either incorporating a recuperator or not will be shown. When no recuperator is included, investments costs
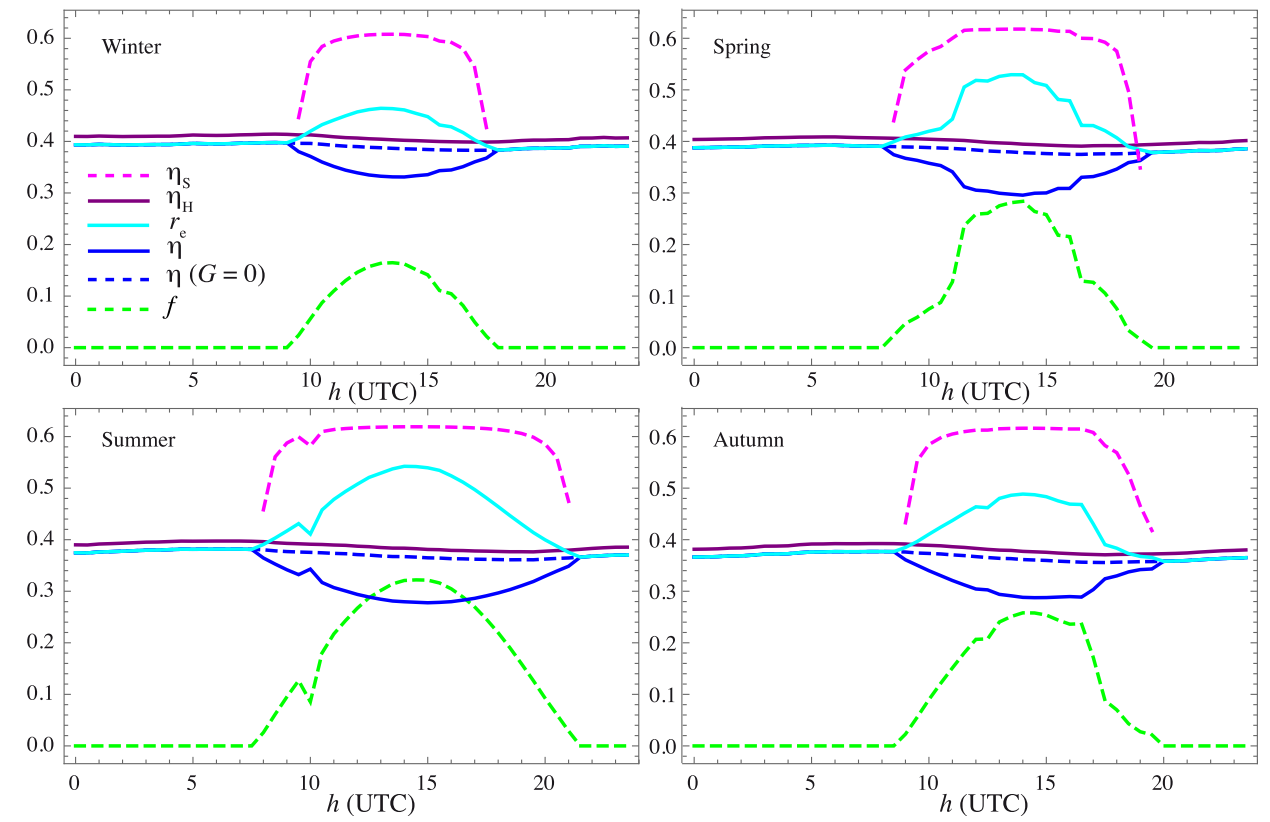

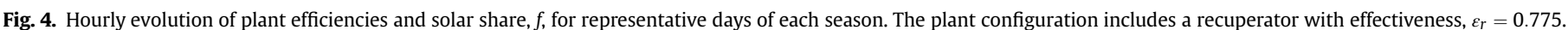


are reduced, thermal efficiency decreases, and fuel consumption is higher. But temperature of the working fluid at the exit of the expansion process is high and so, the cycle is susceptible to be combined with a bottoming cycle. In the opposite situation, when an extra investment is made in the plant and a recuperator is incorporated in the design, fuel costs decrease and thermal efficiency increases, but the temperature at the recuperator exit could make more difficult to use residual heat for bottoming cycles. Moreover, the inclusion of a recuperator will be only beneficial for not too high values of the compressor pressure ratio as discussed elsewhere in the literature $[6,21,22]$.

\section{Model projections}

\subsection{Plant efficiencies and temperatures}

We have obtained the curves for the different thermal plant efficiencies and solar share for a representative day of each season in terms of the UTC time for two plant configurations (see Fig. 1): non-recuperative $\left(\varepsilon_{r}=0\right)$ and recuperative $\left(\varepsilon_{r}=0.775\right)$. These efficiencies are plotted in Fig. 3 (no recuperation is considered) and Fig. 4 (including a recuperator). The efficiency of the solar subsystem, $\eta_{S}$, is only defined when the solar irradiance is enough to deliver an effective heat to the working fluid, so the corresponding curves are plotted for a particular time interval. For any season these curves present a wide plateau during the hours with good insolation and then $\eta_{S}$ decreases during sunrise and sunset. The shape of the functions in these periods is only indicative because a particular model for the evolution of the solar receiver temperature with $G$ during transients should be necessary. This is out of the scope of this work. The plateaus are associated to the fact that solar efficiency are governed by the optical efficiency, $\eta_{0}$, that we considered as constant. The influence of heat losses is small in the shape of $\eta_{S}$, specially in the non-recuperative case (see Fig. 3), only the height of the plateaus is sensitive to the temperature dependent heat losses, Eq. (5). Of course the plateaus are wider during summer, because of the higher number of insolation hours. Largest values of $\eta_{S}$ are about 0.63 for the non-recuperative case and slightly smaller for the recuperative case. This is due to the fact that working temperatures of the solar collector are higher in this case and so heat transfer losses in the solar subsystem are larger.

The efficiency of the Brayton heat engine, $\eta_{H}$, is almost constant, day and night. It depends on the ambient temperature for a particular day but its time dependence is small in the scale of the plots in Figs. 3 and 4. In seasonal terms, $\eta_{H}$, is higher for lower ambient temperatures: winter and spring. Its numerical value significantly increases when incorporating a recuperator, as it should be expected. For instance in winter (see Fig. 3) it amounts approximately 0.29 and with recuperation increases up to 0.41 (see Fig. 4). This represents an increase about $41 \%$ which is very significant. The relative increase is approximately the same in all seasons.

The global plant efficiency, $\eta$, appears as a combination of $\eta_{S}, \eta_{H}$, the efficiency of the combustion process, $\eta_{C}$, and the effectivenesses of heat exchangers (see Eq. (2)). In the absence of insolation, $\eta$ is almost time independent and becomes close to $\eta_{H}$. Numerical differences appear due to the combustion inefficiencies and heat exchanger losses. When the solar receiver begins its contribution as $G$ increases, the solar subsystem is coupled to the turbine and the combustion chamber and so, the global efficiency decreases: it presents a dip during the central hours of the day. The well width depends on the number of insolation hours and its depth of the maximum values that $G$ reaches. In the recuperative configuration, Fig. 4, of course numerical values of $\eta$ are larger than for the nonrecuperative, Fig. 3, one because of the important increase of $\eta_{H}$. For $\varepsilon_{r}=0$, minimum values of $\eta$ change between 0.21 in summer to 0.24 in winter. For $\varepsilon_{r}=0.775$ the smallest value is found in summer, 0.28 , and in winter is around 0.33 .

Although the fuel conversion rate, $r_{e}$, is not strictly a thermal efficiency is also plotted in Figs. 3 and 4. It is identical to $\eta$ during nights because all the heat input is associated to fuel combustion and during the day it has a parabolic shape that resembles the shape of $G$ and qualitatively is like a mirror image of $\eta$. The maximum value of $r_{e}$ appears in summer, when irradiance reaches its higher values: for $\varepsilon_{r}=0$. It amounts 0.35 and for $\varepsilon_{r}=0.775,0.54$ which is a quite interesting value. In the less favorable season, winter, it amounts 0.31 without recuperation and 0.46 with recuperation.
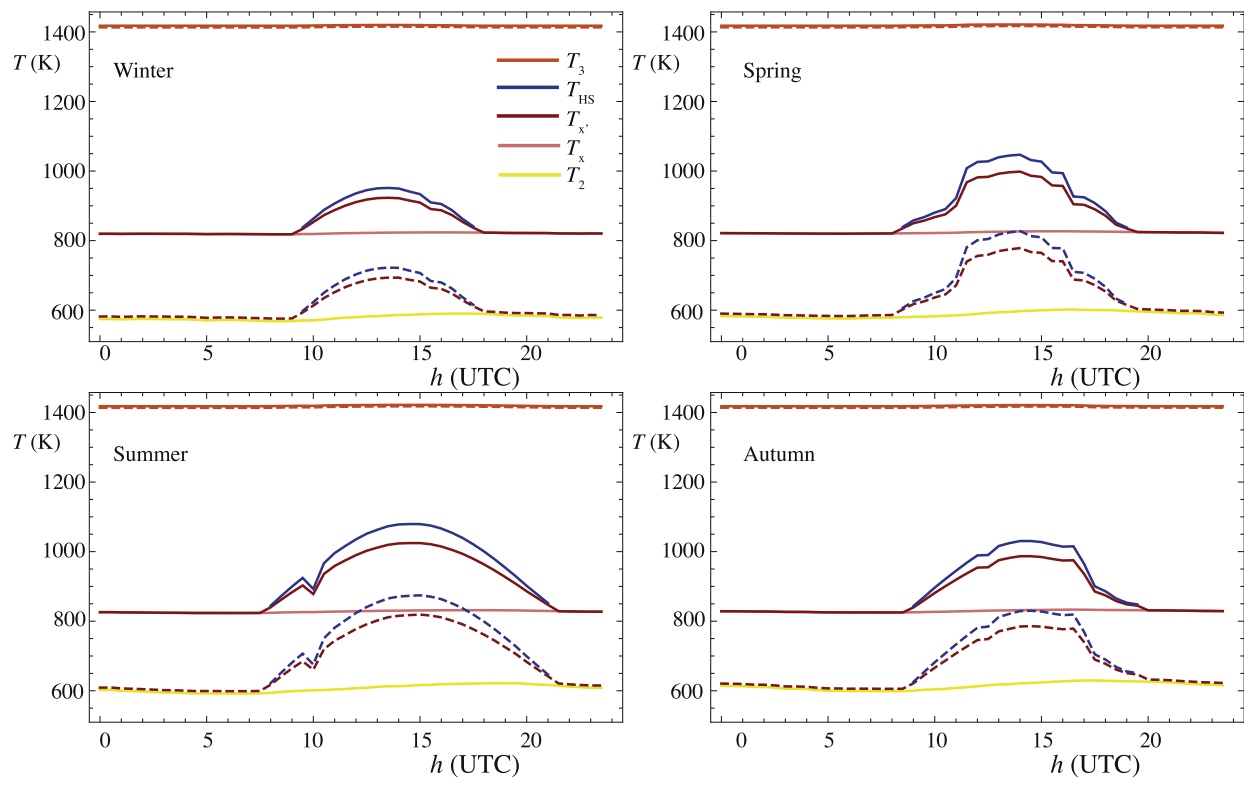

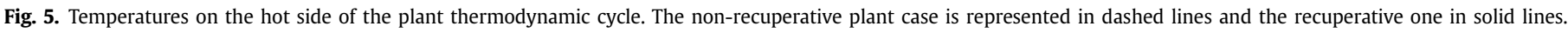
Notation for temperatures corresponds to Fig. 1. 

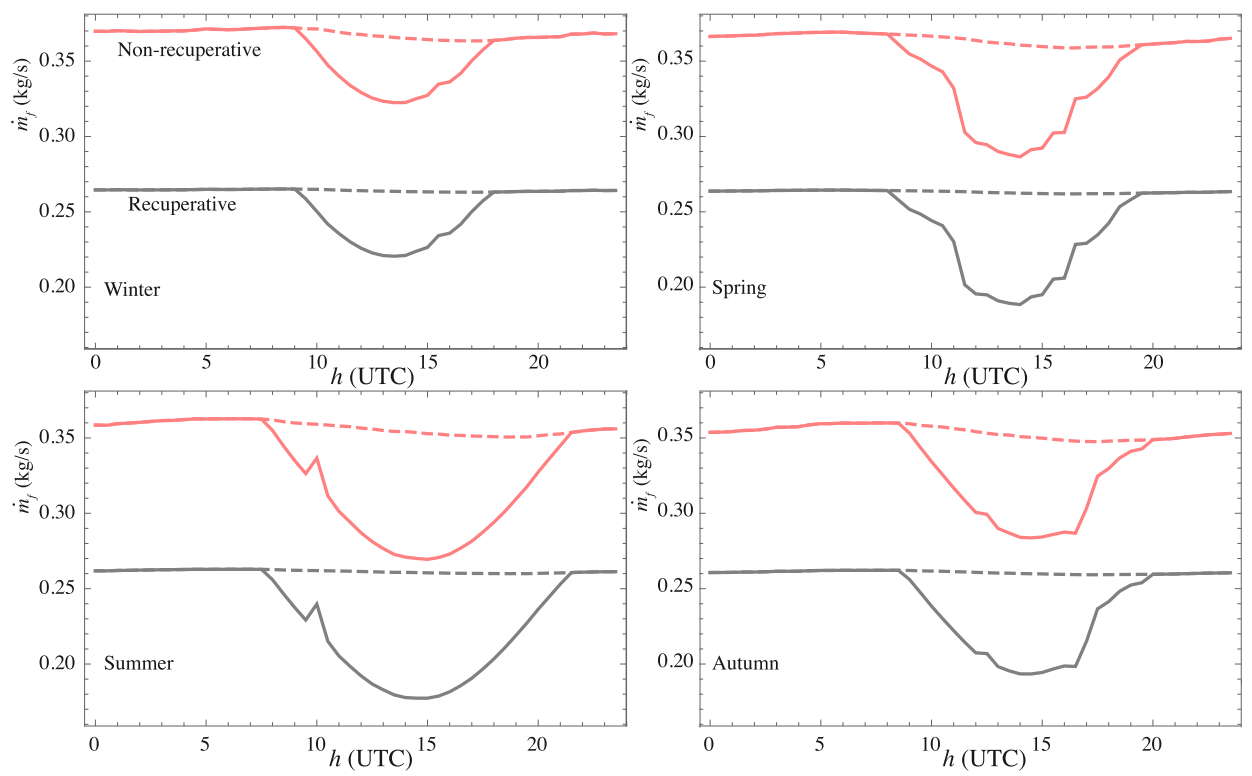

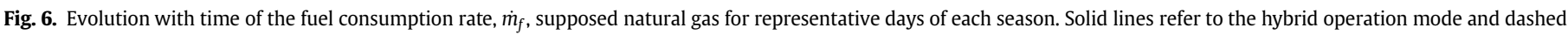
ones to the pure combustion mode.

The solar share, $f$, was defined in Sec. 2 as the ratio between the input heat rate from the solar collector and the total input heat rate. Its evolution with time for the considered representative days is plotted in Fig. 3 (non-recuperative) and Fig. 4 (recuperative). In all cases the shape of $f$ for any particular season reminds that of the solar irradiance, $G$. Differences among seasons refer both to the number of hours with enough solar irradiance and to the height of the curves maxima. For instance in winter for the recuperative configuration $f$ reaches a value slightly above 0.16 and there are $9 \mathrm{~h}$ of effective irradiance. At the other side, for a typical day of summer, $f$ has a maximum around 0.32 and about $14 \mathrm{~h}$ of adequate solar input. When the recuperator is eliminated, for example, with the aim to take advantage of the residual heat in a bottoming cycle, the solar heat input remains the same. Nevertheless, the total heat input (in this case required to increase the temperature from $T_{2}$ to $T_{3}$ instead of from $T_{X}$ to $T_{3}$ ) is larger, so the solar share is smaller. If we compare $f$ in the figure for winter in both configurations, in the recuperative one the maximum is about 0.165 as mentioned above and for the non-recuperative one about 0.121 . This corresponds to a decrease around $36 \%$. At the other end, in summer the maximum with no recuperation is on 0.241 , thus an increase about $34 \%$ is gained with a recuperator.

The temperatures on the heat input steps of the thermodynamic cycle are plotted in Fig. 5. The turbine inlet temperature, $T_{3}$, is almost steady in both configurations as a design criterion, thus providing a stable plant power output. The compressor outlet temperature, $T_{2}$ is around $600 \mathrm{~K}$ and slightly oscillates following the evolution of the surroundings temperature, $T_{L}$. In the nonrecuperative layout, during sun hours the solar receiver increases the temperature of the fluid from $T_{2}$ to $T_{x^{\prime}}$. During this period, the latter has a parabolic shape resembling $G$. The working temperature of the solar collector, $T_{H S}$, is obtained by balancing the energy rate released by the solar collector and that received by the air performing the Brayton cycle. It reaches maximum values above $T_{X^{\prime}}$ because of the losses in the solar receiver. Maximum values of $T_{H S}$ in the non-recuperative situation change from $720 \mathrm{~K}$ in winter to $870 \mathrm{~K}$ in summer.

In the recuperative configuration, the recuperator increases the compressor output temperature $T_{2}$ to a temperature $T_{x}$. Then, the solar collector during the day and the combustion chamber provide the heat rates to reach the turbine inlet temperature, $T_{3} . T_{x}$ is independent of time and season, because it is a function of the turbine outlet temperature $T_{4}$ (almost constant because $T_{3}$ is stable) and the recuperator effectiveness. In the plant considered $T_{X}$ is around $825 \mathrm{~K}$. In this case the temperatures $T_{H S} T_{X^{\prime}}$ are displaced atop around $200 \mathrm{~K}$. During summer, the working temperature of the solar receiver, $T_{H S}$, is slightly above $1000 \mathrm{~K}$, similar to design point conditions of SOLUGAS project. It is important to stress that for the intended power output in this plant $T_{X^{\prime}}$ never reaches the turbine inlet temperature, $T_{3}$. This means that this plant is not dimensioned to work exclusively on solar basis if the aim is to obtain a power output around 4.6 MW. A substantial combustion contribution is always required, even for the highest values of $G$. Some works in the literature report prototype plants working under only solar conditions, but for solar fields relatively larger than the considered here [30].

\subsection{Fuel consumption and emissions}

Numerical computation of the fuel consumption was achieved, either calculating the fuel consumption rate in hourly basis through Eq. (8) or the integrated consumption during a whole day. The mass fuel rate, $\dot{m}_{f}$, (see Fig. 6 ) has two different levels depending on the plant configuration, with or without a heat recuperator. During the night all the electricity generation comes from fuel combustion (natural gas in our case) and differences between recuperative and

Table 1

Fuel consumption for all the seasons as predicted from the simulation model, assuming natural gas fueling.

\begin{tabular}{llllll}
\hline & $m_{f}$ (ton per day) & Winter & Spring & Summer & Autumn \\
\hline No recuperation & Combustion mode & 31.1 & 30.8 & 30.2 & 29.9 \\
& Hybrid mode & 30.3 & 29.2 & 27.6 & 28.3 \\
Fuel saving (\%) & & 2.8 & 5.3 & 8.5 & 5.4 \\
\hline With recuperation & Combustion mode & 22.3 & 22.3 & 22.1 & 22.1 \\
& Hybrid mode & 21.5 & 20.6 & 19.6 & 20.5 \\
Fuel saving (\%) & & 3.9 & 7.3 & 11.5 & 7.5 \\
\hline
\end{tabular}



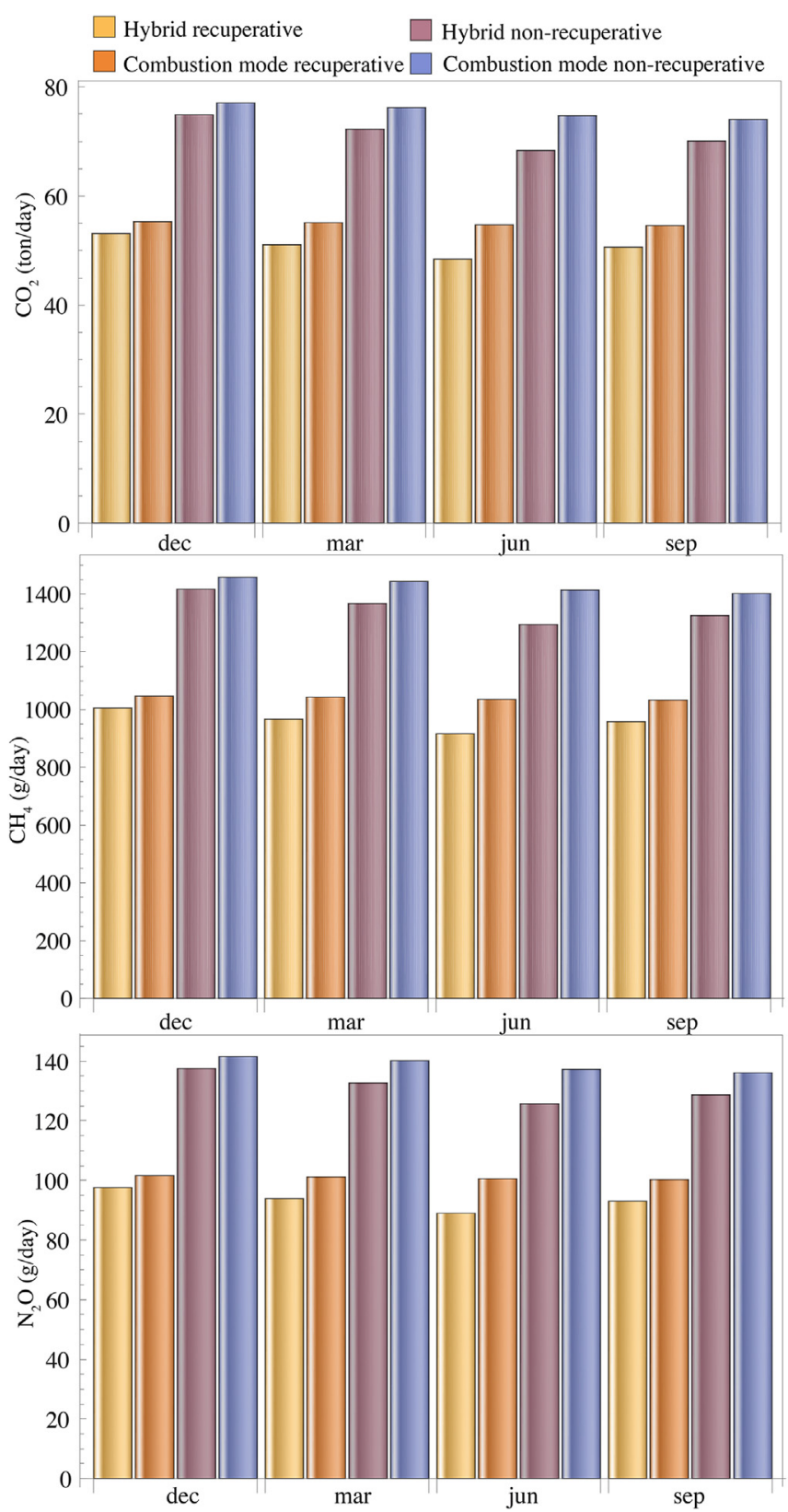

Fig. 7. Real units estimation of greenhouse emissions from the considered model.

non-recuperative cases are around $40 \%$, independently of the season. This is the difference in terms of fuel consumption rate of incorporating a recuperator to pre-heat the working fluid at the compressor exit. When the plant works on a hybrid mode because received irradiance is enough to heat the pressurized air above $T_{2}$ (without recuperation) or $T_{x}$ (with recuperation), the fuel rate saving is important, and obviously depends on seasonal conditions. For each operation mode, the fuel saving for a whole day corresponds to the area of the surface between the solid lines in Fig. 6 (hybrid mode) and the corresponding dashed ones (pure combustion). The results are summarized in Table 1. The legend 'combustion mode' corresponds to the case of no solar heat input and 'hybrid mode' to the case in which solar irradiance is enough for partial heat input coming from the central tower solar plant. For the nonrecuperative plant the saving varies from $2.8 \%$ in winter to $8.5 \%$ in summer. Autumn and spring behave in a similar way, the saving is about 5.3\%. For the recuperative case relative differences are slightly larger: change from $3.9 \%$ in winter to $11.5 \%$ in summer. In autumn and spring, now the saving is around $7.3 \%$.

The differences among plant configurations in fuel consumption are directly transferred to pollutant emissions. As an illustration we have plotted in Fig. 7 a bar diagram with the estimated emissions of the main greenhouse gases in real units: $\mathrm{CO}_{2}, \mathrm{CH}_{4}$, and $\mathrm{N}_{2} \mathrm{O}$. The data in the figure should only be taken as a guide, because each plant could have particular technologies to reduce emissions or $\mathrm{CO}_{2}$ capture mechanisms. The data were obtained from the natural gas emission factors collected in Refs. [31,32]. The figure, in daily basis for the considered particular days of each season, allow to observe two emission levels: the associated to the non-recuperative plant and the one arising from the recuperative one. Differences are substantial as previously commented for fuel consumption. For these two modes, the reduction associated to solar hybridization and its evolution during the year is also apparent.

\section{Summary and conclusions}

A solar hybrid power plant based on a gas turbine following a closed Brayton cycle was modeled from a thermodynamic viewpoint. Plant layout is flexible, it can work either in pure combustion mode (by night or during periods with poor solar irradiation), in a pure solar mode for good solar conditions, and also in a mixed mode with simultaneous solar and combustion heating. A basic objective for plant operation is to produce an stable power output, independent of daily and seasonal variations of solar irradiance and meteorological conditions.

The model allows a direct implementation of dynamic plant operation. The hybridization scheme follows a serial or sequential heat input divided in several steps. For instance, in the case of a recuperative plant layout and hybrid operation, the working fluid is heated up first in the recuperator by making use of the high temperatures at the turbine exit, then in the solar receiver of the central tower collector, and finally in the combustion chamber.

The thermodynamic model for the Brayton cycle incorporates the most important irreversibility sources in real facilities. But at the same time, it was avoided to introduce a huge number of parameters. This allows an entirely analytical simulation scheme where it is easy to check the influence of the most important plant design parameters. Dry air is taken as working fluid. The dependence with temperature of specific heats is explicitly considered provided that temperature variations along the cycle are large.

The solar collector was considered as an array of mirrors that collect the solar power on the top of a central tower receiver. It was modeled in an straightforward way, incorporating optical losses as well as heat losses in the solar collector due to radiation and conduction/convection terms. The optical efficiency was taken an averaged effective factor. The overall plant efficiency was obtained as a combination of the efficiency of the plant subsystems (solar, combustion, and gas turbine) and the effectivenesses of the heat exchangers connecting subsystems. The SOLUGAS project [26] in Spain was elected to take the parameters for obtaining numerical results. The model was validated in previous works by comparing with experimental measures in this installation, assuming fixed design point conditions [18].

In order to obtain representative predictions, real seasonal data for solar irradiance and ambient temperature were incorporated to our computational model. Typical days for each season were considered. The evolution of global plant thermal efficiency, efficiencies of the subsystems, solar share, power output, and fuel conversion rate was computed in hourly basis. Numerical results for fuel consumption rate and greenhouse gases inventory were presented and analyzed. The predictions of our model reveal that 
the combination of a central tower solar installation in association to a closed gas turbine and a backup combustion chamber burning natural gas has a good potential to produce stable power output in the range of a few megawatts with low fuel consumption, and so considerable lower pollutant emissions compared with a standard pure combustion plant.

\section{Acknowledgements}

The authors acknowledge financial support from MINECO of Spain, Grant ENE2013-40644-R.

\section{References}

[1] M. Romero, A. Steinfeld, Concentrating solar thermal power and thermochemical fuels, Energy Environ. Sci. 5 (2012) 9234-9245.

[2] O. Behar, A. Khellaf, K. Mohammedi, A review of studies on central receiver solar thermal power plants, Rene. Sust. Energy Rev. 23 (2013) 12-39.

[3] P. Schwarzbözl, R. Buck, C. Sugarmen, A. Ring, M. Marcos Crespo, P. Altwegg, J. Enrile, Solar gas turbine systems: design, cost and perspectives, Sol. Energy 80 (2006) 1231-1240.

[4] Tech. rep., Solar-hybrid Power and Cogeneration Plants, European Commission, 2011 ordis.europa.eu/publication/rcn/13318_en.html.

[5] R. Korzynietz, M. Quero, R. Uhlig, SOLUGAS-future Solar Hybrid Technology, Tech. rep., SolarPaces, 2012, http://cms.solarpaces2012.org/proceedings paper/7ee7e32ece8f2f8e0984d5ebff9d77b.

[6] M. Dunham, B. Iverson, High-efficiency thermodynamic power cycles for concentrated solar power systems, Renew. Sust. Energy Rev. 30 (2014) $758-770$.

[7] G. Barigozzi, A. Perdichizzi, C. Gritti, I. Guaiatelli, Techno-economic analysis of gas turbine inlet air cooling for combined cycle power plant for different climatic conditions, Appl. Therm. Eng. 82 (2015) 57-67.

[8] E. Okoroigwe, A. Madhlopa, An integrated combined cycle system driven by a solar tower: a review, Renew. Sust. Energy Rev. 57 (2016) 337-350.

[9] B. Grange, C. Dalet, Q. Falcoz, F. Siros, A. Ferrière, Simulation of a hybrid solar gas-turbine cycle with storage integration, Energy Proc. 49 (2014) 1147-1156.

[10] E. Okoroigwe, A. Madhlopa, Evaluation of the Potential for Hybridization of Gas Turbine Power Plants with Renewable Energy in South Africa, IEEE Conference Publications, 2015, http://dx.doi.org/10.1109/DUE.2015.7102985.

[11] J. Spelling, Hybrid Solar Gas-turbine Power Plants, Ph.D. thesis, KTH Royal Institute of Technology, Department of Energy Technology, Stockholm, Sweden, 2013.

[12] Y. Li, S. Liao, G. Liu, Thermo-economic multi-objective optimization for a solardish Brayton system using NSGA-II and decision making, Elect. Power. Energy Sys 64 (2015) 167-175.

[13] G. Barigozzi, G. Bonetti, G. Franchini, A. Perdichizzi, S. Ravelli, Thermal performance prediction of a solar hybrid gas turbine, Sol. Energy 86 (2012)
2116-2127.

[14] F. Collado, J. Guallar, A review of optimized design layouts for solar power tower plants with campo code, Ren. Sust. Energy Rev. 20 (2013) 142-154.

[15] R. Soltani, P. Keleshtery, M. Vahdati, M. Khoshgoftar Manesh, M. Rosen, M. Amidpour, Multi-objective optimization of a solar-hybrid cogeneration cycle: application to CGAM problem, Energy Conv. Manage 81 (2014) 60-71.

[16] A. McMahan, S. Klein, D. Reindl, A finite-time thermodynamic framework for optimizing solar-thermal power plants, J. Sol. Energy Eng. 129 (2007) $355-362$.

[17] W. Le Roux, T.M.J. Bello-Ochende, A review on the thermodynamic optimisation and model of the solar thermal Brayton cycle, Renew. Sust. Energy Rev. 28 (2013) 677-690.

[18] D. Olivenza-León, A. Medina, A. Calvo Hernández, Thermodynamic modeling of a hybrid solar gas-turbine power plant, Energy Convers. Manage 93 (2015) 435-447.

[19] M.J. Santos, R.P. Merchán, A. Medina, A. Calvo Hernández, Seasonal thermodynamic prediction of the performance of a hybrid solar gas-turbine power plant, Energy Convers. Manage 115 (2016) 89-102.

[20] R.P. Merchán, M.J. Santos, I. Reyes-Ramírez, A. Medina, A. Calvo Hernández, Modeling hybrid solar gas-turbine power plants: thermodynamic projection of annual performance and emissions, Ener. Conv. Manage 134 (2017) $314-326$.

[21] S. Sánchez-Orgaz, A. Medina, A. Calvo Hernández, Recuperative solar-driven multi-step gas turbine power plants, Energy Convers. Manage 67 (2013) $171-178$.

[22] S. Sánchez-Orgaz, M. Pedemonte, P. Ezzatti, P. Curto-Risso, A. Medina, A. Calvo Hernández, Multi-objective optimization of a multi-step solar-driven Brayton cycle, Energy Convers. Manage 99 (2015) 346-358.

[23] J. Heywood, Internal Combustion Engine Fundamentals, McGraw-Hill, 1988.

[24] J. Duffie, W. Beckman, Solar Engineering of Thermal Processes, John Wiley and Sons, Hoboken, New Jersey, 2006.

[25] L. Weinstein, J. Loomis, B. Bhatia, D. Bierman, E. Wang, G. Chen, Concentrating solar power, Chem. Rev. 115 (2015) 12797-12838.

[26] R. Korzynietz, J.A. Brioso, A. del Río, M. Quero, M. Gallas, R. Uhlig, M. Ebert, R. Buck, D. Teraji, Solugas - comprehensive analysis of the solar hybrid Brayton plant, Sol. Ener 135 (2016) 578-589.

[27] S. T. Caterpillar, https://mysolar.cat.com/cda/files/126873/7/dsm50pg.pdf. URL https://mysolar.cat.com/cda/files/126873/7/dsm50pg.pdf.

[28] E.W. Lemmon, M.L. Huber, M.O. McLinden, NIST Standard Reference Database 23: Reference Fluid Thermodynamic and Transport Properties-REFPROP, Version 9.1, National Institute of Standards and Technology, Standard Reference Data Program, Gaithersburg, 2013.

[29] Meteosevilla. http://www.meteosevilla.com. URL http://www.meteosevilla. com.

[30] A. Kribus, P. Doron, R. Rubin, R. Reuven, E. Taragan, S. Duchan, J. Karni, Performance of the directly irradiated annular pressurized receiver (DIAPR) operating at 20 bar and $1200^{\circ}$ C, J. Sol. Energy Eng. 123 (2001) 10-17.

[31] Direct Emissions from Stationary Combustion Sources, May 2008. www.epa. gov/climateleaders.

[32] Emission Factors for Greenhouse Gas Inventories, April 2014. http://www.epa. gov/climateleadership/documents/emission-factors.pdf. 